\title{
REDESCRIC̣ÃO DE ALGUNS EXEMPLARES TIPOS DE ESPÉCIES NEOTROPICAIS DE TETRAPEDIA KLUG, DESCRITOS POR FRIESE EM 1899 (APOIDEA, ANTHOPHORIDAE). \\ I. ESPÉCIES PERTENCENTES A TETRAPEDIA (S. STR.) ${ }^{1}$
}

\author{
Jesus S. Moure ${ }^{2}$
}

\begin{abstract}
RIDESCRIPTION OF SOME TYPE SPECIMENS OF NEOTROPICAL SPI.CIES OF TETRAPEDIA KIIUG, DISCRIBID BY FRIESE 1899. (APOIDIA. ANTHOPHORIDAE). I. Spectes belonging to TEtRapedia (S. STR.). The type specimens of Neotropical Tetrapedia (s. str.) described by Friese, 1899. namely $T$. peckoltii. $T$. curvitarsis. $T$. amplitarsis and T. pramidalis are redescribed. T. ranthostigma Schrottky, 1913 , is considered as synonym of $T$. pramidalis Friese. 1899.

KEY WORDS. Apoidea. Anthophoridae. Tetrapedia. Neotropical. systematics. synonymy
\end{abstract}

Nos anos 1956-57 como bolsista da Fundação Rockefeller e da CAPES, nos Estados Unidos, e 1957-58 como bolsista da National Science Foundation por meio da Universidade de Kansas, na Europa, tive oportunidade de estudar grande parte dos tipos de Apoídeos da Região Neotropical. Infelizmente, por razōes peculiares ao período de minha visita à Alemanha, foi-me impossível o acesso ao Museu Zoológico de Berlim e depois de 10 dias de tentativas inúteis, profundamente frustrado com essa falha fundamental $\mathrm{em}$ minhas notas, fui para Copenhagen estudar os tipos das espécies neotropicais de abelhas descritas por Fabricius.

Em várias ocasiōes, por intermédio de amigos, foi-me dado estudar alguns desses tipos (Xylocopini e Euglossini) que dei a conhecer há uma vintena de anos atrás.

Agora graças ao interesse demostrado pelo Museu de Munich e intermediação de vários amigos tive acesso a alguns exemplares tipos da Coleção Friese, propriedade do Museu Zoológico da Universidade Humboldt, Berlim, descritos por esse autor dentro de um conceito amplo de Tetrapedia Klug, 1810.

Incluo nesta primeira parte as espécies pertencentes à Tetrapedia s. str. (espécie tipo Tetrapedia diversipes Klug, 1810), no sentido mais restrito delineado no trabalho feito por MiCHENER \& MOURE (1957).

\section{TERMINOLOGIA EMPREGADA}

As medidas são feitas com ocular micrométrica numa WILD-M5, e enunciadas em centésimos de milímetro.

1) Contribuição número 815 do Departamento de Zoologia. Universidade Federal do Paraná.

2) Departamento de Zoologia. Universidade Federal do Paraná. Caixa Postal 19(2)(). 81531-990) Curitiba. Paraná. Brasil. Bolsista do CNPy. Proc. 205585/76. 
O comprimento dos pêlos ou cerdas é aproximado, em "micra", medido com 50x, mais raramente com 100x.

Ao indicar proporções, estas são em geral aproximadas.

Denomino como "sola" a face interna do basitarso posterior dos machos, mais ou menos plana e geralmente delimitada por bordos bem evidentes; estes podem ser inermes ou armados com uma saliência ou um dente perpendicular ao bordo (como em Tetrapedia diversipes). As medidas referem-se ao comprimento do basitarso ou especificamente, da sola, iniciando-se pelo comprimento total e as larguras da base para o ápice.

Os intervalos entre os pontos estão indicados pelo número de "diâmetros de ponto" que os separam, assim um intervalo de três diâmetros é simplesmente indicado com $3 \mathrm{dp}$.

Chamo de "dobra mesepisternal" a aresta de encontro entre as faces anterior e lateral do mesepisterno: pode ser simplesmente arredondada, ou moderada, ou em aresta viva, mais ou menos careniforme, deixando na face lateral uma depressão bem perceptível.

\section{Tetrapedia peckoltii Friese, 1899}

Tetrapedia peckoltii Friese, 1899. Ann. k.k. Naturhist. Hofmus. 14 (3): 282.

Brasil, Rio de Janeiro: Rio de Janeiro, exemplar macho, depositado no Museu de Berlim, designado aqui como Lectótipo. Em bom estado de conservação.

Diagnóstico. "Nigra, nigro-hirta, ut diversipes, sed major, clypeo punctato, segmento medio grosse punctato, $\sigma$ segmentorum basi caerulea, segmentis ventralibus 2.-4. albido-tomentosis, segmento 3. longissime albido-fimbriato, pilis lateralibus incurvatis, coxis posticis bigibbosis, trochanteribus unigibbosis, metatarsis curvatis, marginatis, sed inermibus. Tetrapedia peckoltii ist grösser als diversipes, Clypeus deutlich punktirt, das ganze Mittelsegment grob punktirt, dem $\checkmark$ fehlt der stumpfe Zahn am Metatarsus, und die Basis der Segmente ist blaugrün."

Macho. De tamanho relativamente grande. Comprimento total aproximado $10,83 \mathrm{~mm}$, da asa anterior $9,15 \mathrm{~mm}$; largura da cabeça $3,20 \mathrm{~mm}$ e do segundo tergo $3,45 \mathrm{~mm}$.

Preto, com reflexos de azul-aço na base dos tergos (bem evidente nos tergos segundo e quarto e nos lados do quinto e sexto), sétimo com reflexos verdebrônzeo-claros, em parte purpúreos; margens dos tergos um tanto desbotadas. Pernas médias e posteriores castanho-ferrugíneas, terço apical das tíbias e os basitarsos posteriores ferrugíneo-amarelentos. Tégulas pretas; asas pardo-ocráceas, um tanto fuscas; estigma e venação mais escuros.

Pilosidade predominante preta; branco-plumosa na parte inferior da fronte com algumas cerdas pretas misturadas, nas áreas paroculares desde os álvéolos para baixo, alguns pêlos no clípeo e no labro; nas genas e no vértice preta. No escutelo algumas cerdas chegam a 1100 micra; nos esternos alguns pêlos brancos; branca no lado externo das tíbias e tarsos médios, nos fêmures posteriores em cima, tíbias no ápice e em franja alargada para a base nos basitarsos. Nos três 
primeiros tergos fina e esparsa no disco, aos lados quase nula, porém demarcando a depressão marginal glabra; mais densa no quarto antes das depressões, no quinto e sexto formando densa franja plumosa esbranquiçada precedida por cerdas pretas eretas mais longas e um tanto misturadas às franjas lateralmente. Nos esternos segundo ao quarto com cobertura apical progressivamente mais larga e mais densa de uma pilosidade branca plumosa decumbente, no terceiro e quarto com cerdas ligeiramente pardo-ocráceas longas, voltadas para o meio, mais desenvolvidas no terceiro; quinto largamente liso e polido, inteiramente glabro; na metade basal do sexto com uma série diversificada a cada lado micro-reticulada e com pilosidade curta e densa, seguida no meio por cerdas longas voltadas para trás e terminando a cada lado com uma série de cerdas grossas mais curtas e apertadas entre si, voltadas para dentro e para trás, como que pectinadas, a parte distal microreticulada, canaliculada, bordo apical em arco levemente sinuado no meio cercando a metade distal concava em vista inferior.

Pontuação grossa na fronte, esparsa, com os intervalos lisos 2-4dp (diâmetros de ponto), deixando grande área lisa triangular frente ao ocelo médio, situado em área deprimida mais ou menos largamente ligada à outra área lisa a cada lado dos ocelos laterais; no vértice mais fina e mais numerosa, os intervalos 1,5-2 dp; no clípeo mais esparsa que na fronte com alguns micro-pontos intercalados e, uma linha transversal pré-apical de pontos no terço médio; mais numerosa nos declives laterais; quase toda área supraclipeal lisa, com alguns micro-pontos no disco, mais grossos e esparsos no declive para os alvéolos; nas paroculares inferiores fina, coberta pela pilosidade branca. No mesoscuto como na fronte, com área de pontuação mais esparsa entre o sulco médio e as parápsides e micro-pontos intercalados; mais regular e mais densa (1,5-2dp) nos cantos anteriores; no escutelo semelhante à dos cantos anteriores, um pouco mais densa deixando linha lisa vaga ao longo do meio; no metanoto quase como no escutelo; nos mesepisternos bastante mais esparsa com intervalos entre 5-8dp. Na área basal e nos flancos do propódeo quase tão densa como no escutelo, um pouco menos abaixo da área basal, toda micro-reticulada. Nos três primeiros tergos moderadamente esparsa no disco e marcando os limites das depressões marginais, quase nula aos lados; no quarto e principalmente no quinto e sexto mais densa para implantação das franjas apicais.

Cabeça pouco mais larga que longa; olho mais de duas vezes sua largura, genas de perfil menos da metade dessa largura (210: 100: 40); face convergente para baixo com a interorbital máxima menor que o comprimento do olho (170: 175: 140); clípeo 1,6 vezes mais largo que longo, tão largo como a distância clipeocelar (80: 130: 130), os cantos látero-inferiores arredondado-deprimidos finamente rebordados; área malar linear (3); supraclipeal um pouco elevada em triângulo, o sulco frontal reduzido a um ponto alongado entre os alvéolos; distância interalveolar quase 2,5 diâmetros de alvéolo e a alveolorbital um diâmetro e meio (57: 30: 80: d 24); paroculares planas; ocelo médio dentro de uma depressão circundante; distância interocelar igual à ocelorbital, pouco menor que dois diâmetros do ocelo médio (44:20: d 27); vértice estreito, cerca de $2 / 3$ do diâmetro do ocelo. Labro trapezóide, fracamente deprimido ao longo do meio, duas vezes mais largo que longo, seu bordo anterior sinuado. Escapo subcilíndrico, três vezes 
e meia seu diâmetro (70/20), um pouco mais curto que a distância alveolocelar (80), cerca de $2 / 9$ do comprimento do flagelo e pedicelo juntos (320); pedicelo elipsóide, mais longo que seu diâmetro; flagelômero basal levemente obcônico, duas vezes seu diâmetro; segundo igual ao próprio diâmetro, terceiro e quarto pouco mais longos $(40: 22: 24: 25: \mathrm{d} 22)$. Dobra mesepisternal anterior fraca a moderada. Fêmures e principalmente as tíbias posteriores muito inchados (300: 120), estas com franja muito desenvolvida (pêlos plumosos até 1200 micra); Jasitarso longo (220), arqueado, alargado para o ápice arredondado (100) em vista lateral e afilado em vista interna, com a sola em plano inclinado para a base, estreitada até cerca da metade da sua distância à base, inerme, com densa franja plumosa posterior, mais larga na base (1200 micra) e estreitada para o ápice, aí com cerdas fortes (até 600 micra). Último tergo arqueado, com o bordo fracamente sinuado.

Apesar das muitas coletas na Floresta da Tijuca e nos arredores do Rio de Janeiro, o Dr. C.A. Campos Seabra e colaboradores até a data não reencontraram esta espécie.

\section{Tetrapedia curvitarsis Friese, 1899}

Tetrapedia curvitarsis Friese, 1899. Ann. k.k. Naturhist. Hofmus. 14 (3): 283

BRASIL, Espírito Santo: Santa Leopoldina, macho, Michaelis leg., aqui designado Lectótipo. Etiquetas originais: "S. Leopold/ina / Tetrapedia o" curvitarsis det Friese 1898 n.sp./Type/em vermelho e em amarelo claro:/ Zool. Mus. Berlin /.

Diagnóstico. " $\sigma$ ". Nigra, nigro-hirta, ut peckoltii, sed abdomine segmento 7. evidenter emarginato, ventre fusco-fimbriato, tibiis posticis evidenter incrassatis, metatarsis curvatis, dilatatis torquatisque, apice basi latiore. Tetrapedia curvitarsis steht der peckoltii sehr nahe, doch sind der Hinterbeine viel auffallender verdickt und Tibien kolossal erweitert, die Metatarsen wohl ähnlich gebildet, aber eigenartig verdreht und massiver gebaut, dabei an der Spitze eckig vorspringend und viel breiter als an der Basis und als bei peckoltii. Bauch ist dunkel befranst, das siebente Dorsalsegment auffallend ausgerandet, die Ecken gerundet. 10 bis $10-1 / 2 \mathrm{~mm}$. Lang. Mir liegen $3 \sigma^{*}$ von S. Leopoldina (Minas Gerais, Michaelis) vor Brasilia."

Na etiqueta de procedência, impressa, está S. Leopoldo, com correção manuscrita para S. Leopoldina pelo mesmo Friese. São Leopoldo está no Rio Grande do Sul, uns $40 \mathrm{~km}$ ao norte de Porto Alegre. O "o" final foi corregido para "ina", mas houve engano ao registrar essa localidade em Minas Gerais. Santa Leopoldina fica no Espírito Santo, na margem direita do rio Vitória, uns $50 \mathrm{~km}$ ao noroeste da capital do Estado.

Macho de porte grande. Comprimento total aproximado $10,83 \mathrm{~mm}$, da asa anterior $9,25 \mathrm{~mm}$; largura da cabeça $3,44 \mathrm{~mm}$ e do segundo tergo abdominal $2,40 \mathrm{~mm}$.

Preta; flagelo por baixo castanho-ferrugíneo; pernas castanho-escuras; 
tíbias posteriores de um castanho mais claro, os 3/8 distais amarelo-ferrugíneos; desta cor os basitarsos, com os bordos da sola um pouco enegrecidos. Tégulas castanhas; asas lavadas em ocráceo, mais escurecidas nas células radial e primeira média; estigma e venação méleos; hâmulos 10.

Pilosidade predominante preta. Pêlos brancos plumosos na base da fronte, nas paroculares (formando pequeno tufo junto às fóveas tentoriais), nos lados do clípeo e nas genas; em flocos plumosos curtos em volta dos lobos pronotais e nas crestas axilares. Pálido-ocrácea no labro e formando uma mancha alongada ánteroexterna nas tíbias médias. Nas coxas anteriores curta e esparsa. Amareloferrugíneo-clara no terço distal das tíbias posteriores e toda a franja e cerdas dos basitarsos do mesmo par. Nos quatro tergos anteriores curta e mais numerosa, faltando nas elevações laterais antes das depressões marginais; no quinto e sexto formando franja denso-plumosa com cerdas longas entremeadas; no sétimo mais curta e mais esparsa; nos esternos as fímbrias pálidas, as cerdas mais longas marginais dos esternos terceiro e quarto curvadas para dentro.

Pontuação na fronte fina (dp 20-25 micra), os intervalos lisos um pouco maiores ( $1,5 \mathrm{dp}$ ), para os lados e nas paroculares mais esparsa ( $2-3 \mathrm{dp}$ ); áreas lisas ante-ocelares descontinuas; densa no vértice; no clípeo mais grossa (40 micra), bastante irregular, esparsa (3-4 dp), na supraclipeal ainda mais esparsa. No mesoscuto densa (30 micra) ao longo do meio, os intervalos quase careniformes, no restante os intervalos lisos (1,2-2 dp) e com uma área pequena mais lisa ( $3 \mathrm{dp}$ ) a cada lado no disco entre as parápsides e o sulco médio; no escutelo um pouco mais densa, sem linha média, a faixa lisa posterior pouco nítida e estreitada para os lados; no metanoto igual, com os intervalos reticulados; na depressão lateral dos mesepisternos mais grossa (40 micra) e mais esparsa, os intervalos lisos (3-6 dp), para cima e para trás mais densa, na face anterior à dobra mais fina e mais densa, os intervalos lisos (1,5-2 dp); nos metepisternos bastante densa em cima, na frente e abaixo do espiráculo com alguns pontos, os intervalos parcialmente reticulados. Propódeo todo micro-reticu-lado, a pontuação na área basal moderadamente densa, mais esparsa para baixo sem chegar a formar limite em V aberto, a linha média obsoleta; muito densa nos flancos adiante do espiráculo, menos densa para baixo e quase nula na extremidade inferior. Nos quatro primeiros tergos fina e moderamente densa na maior parte do disco, as tumescências precedentes às depressões marginais absolutamente lisas; no quarto um pouco mais forte, aos lados a base quase inteiramente lisa; no quinto e sexto adensada; no sétimo moderadamente densa.

Olhos grandes, duas vezes sua largura; genas estreitas, menos da metada da largura do olho; malar linear; órbitas internas fracamente sinuadas, mais convergentes em baixo, a interorbital máxima cerca de 10/11 do comprimento do olho; clípeo abaulado, um pouco achatado no disco e fracamente deprimido na parte transversal da sutura epistomal, 1,75 vezes mais largo que longo, seu comprimento $3 / 5$ da distância ao ocelo médio, com a depressão ou faixa marginal pouco definida; sutura subantenal 1,4 vezes o diâmetro alveolar; supraclipeal abaulada aos lados e sub-plana no disco; interalveolar 2,6 vezes e a alveolorbital 1,4 vezes o diâmetro do alvéolo; sulco frontal evidente na extremidade superior 
da supraclipeal e bastante deprimido na área anteocelar; distância interocelar, em vista anterior, quase igual à ocelorbital (1,7 d). Labro fracamente deprimido ao longo do meio, truncado apicalmente com os cantos arredondados, 1,7 vezes mais largo que longo, pouco pontuado, os intervalos lisos. Escapo 2,6 vezes mais longo que seu diâmetro, subcilíndrico, cerca de $2 / 9$ do comprimento do flagelo e pedicelo juntos, mais longo que os dois primeiros flagelômeros combinados; flagelômero basal duas vezes o segundo, terceiro e quarto subiguais e mais longos que seu diâmetro $(1,3)$. Sulco médio do mesoscuto muito evidente, deprimido; dobra mesepisternal forte, completa, em carena aguda, a depressão lateral bem marcada; fêmures anteriores muito alargados na base articular com o torcanter (160: 80: 40: 35 ), formando como que um cotovelo muito forte em esquadro; coxas posteriores de perfil côncavo, as saliências na base e, no ápice, em curta lamela de contorno arredondado e os torcanteres apicalmente com lamela semelhante; fêmures tão grossos como a metade do comprimento (240: 120); tíbias claviformes, mais longas e mais grossas que os fêmures (320: 140); basitarso com o bordo posterior quase reto e o anterior côncavo, alargado para o ápice (240: 30: 30: 40), a sola mais curta que o basitarso, mais larga e angulosa na base, em seguida estreitada e novamente alargada para o ápice parabolóide (150: 49: 25: 30), no quinto distal com uma carena elevada em curva entre os bordos, com franja larga na base e atenuada para o ápice (800: 400 micra), com o tufo de cerdas da face interna muito deslocado para a margem posterior e com umas poucas cerdas onduladas curtoplumosas muito longas (até 1200 micra), implantadas junto à base. Tergos com o bordo apical desbotado e fracamente sinuado; último com o bordo translúcido, emarginado mais profundamente.

Na descrição Friese afïrma que esta espécie fica muito próxima à $T$. peckoltii. Com os dois tipos em mão, anoto abaixo, as principais diferenças entre ambos:

\section{T. peckoltii}

a) Pilosidade branca muito desenvolvida, cobrindo grande parte da fronte e paroculares; com larga estria ântero-externa nas tíbias médias e toda face externa dos basitarsos; tufo amarelo-esbranquiçado na metade distal dos fêmures posteriores; franja dos basitarsos desta mesma cor Cerdas longas dos esternos 3-4 brancocremosas até o ápice.

b) Fêmures anteriores fracamente claviformes, estreitados suavemente desde o terço basal para a articulação do trocanter.

c) Basitarso posterior estreito, de bordos paralelos, fortemente alargado para o ápice: proporções 240:40:40:90.

\section{T. curvitarsis}

a) Pilosidade branca escassa na face, com longas cerdas pretas na fronte; tufos bran$\cos$ junto às fóveas tentoriais pequenos; estria ântero-externa das tíbias médias acastanhado-escura; basitarsos preto pilosos; tufo pálido-fulvo na metade distal dos fêmures posteriores; franja dos basitarsos desta mesma cor. Cerdas longas dos esternos 3-4 escurecidas no ápice.

b) Fêmures anteriores fortemente alargados para à base em cotovelo, estreitados abruptamente para a articulação com o trocanter.

c) Basitarso posterior inicialmente estreitado e depois alargado para o ápice projetado: proporçōes: 180:72:60:90. 
T. peckoltii

d) Sola definida apenas no terço basal, apicalmente plana, alargada e retorcida para dentro com o bordo externo muito mais elevado; proporções 84:34:115. Sem carena média arqueada no terço distal.

e) Base dos tergos 2-6 com brilho azul-aço; sétimo tergo com reflexos verde-brônzeo passando a púrpura-violeta.

f) Tergos 4-6 com franjas, em 5-6 densoplumosas, cremosas; no sétimo com franja branca.
T. curvitarsis

d) Sola definida por fortes carenas, alargada angularmente no terço basal, fortemente estreitada nos dois tercos distais, os bordos subparalelos: proporções: 52:25:28. Com carena média arqueada distal.

e) Base dos tergos 2-7 pretos; sétimo tergo castanho-escuro, o bordo apical translúcido.

f) Tergos 5-6 com franjas distais plumosas, pretas; sétimo sem franja de pêlos plumosos.

\section{Tetrapedia amplitarsis Friese, 1899}

Tetrapedia amplitarsis Friese, 1899. Ann. k.k. Naturhist. Hofmus.. Wien, 14 (3): 283.

Brasil, São Paulo: Jundiaí, fêmea, 21-I-1899. Exemplar em perfeito estado de conservação.

Diagnóstico. "Nigra, nigro-hirta, capite albido-hirto, $\$$ scopa fere tota flavida, thoracis segmento medio impunctato. $\sigma$ " coxis posticis dente curvato, metatarsis apice lobiformiter dilatato.

Tetrapedia amplitarsis ist im $\$$ durch fast ganz gelbliche Scopa und das unpunktierte Mittelsegment ausgezeichnet, das $\sigma \mathbf{~ h a t ~ l a n g ~ b e d o r n t e ~ H i n t e r h u ̈ f t e n ~}$ und blattförmig verbreiterten Metatarsus."

E no fim da descrição: "Tetrapedia amplitarsis ist die grösste Art, mir lagen Exemplare vom Mus. Berlin, Wien und aus der Coll. Saussure vor; Brasilia."

Fêmea, relativamente grande. Comprimento total aproximado $10,15 \mathrm{~mm}$, da asa anterior $8,75 \mathrm{~mm}$; largura da cabeça $3,6 \mathrm{~mm}$ e do segundo tergo $3,43 \mathrm{~mm}$.

Preta; escapo pardo-escuro, extremidades das tíbias e basitarsos posteriores castanho-ferrugíneos, esporões castanho- escuros, distitarsos pardo-ferrugíneos, unhas com as pontas pretas. Tégulas castanho-pardas; asas escurecidas, mais nas regiōes costal e marginal; estigma pardo-ferrugíneo, venação escura.

Pilosidade preta, mesmo no clípeo, paroculares, supraclipeal e labro, porém amarelo-ferrugínea na metade distal das tíbias e nos basitarsos posteriores. Bastante esparsa na face e no vértice (algumas cerdas até 600 micra e nas genas 700 micra); as cerdas simples, não plumosas. Esparsa no mesoscuto, escutelo (até 500 micra) e mesepisternos. Esparsa nos flancos do propódeo, nula na área basal. Curta e muito esparsa nos três primeiros tergos; numerosa, muito curta (cerca de 100 micra) aos lados do primeiro; curta (200 micra) nos tergos quarto e quinto, muito esparsa no disco, mais numerosa e mais longa (400 micra) para os lados, ge-ralmente simples ou apenas algumas ramificadas; nos esternos mais numerosa e mais longa (até 1000 micra), as franjas pretas com algumas cerdas pálidas misturadas. 
Pontuação moderadamente grossa e esparsa na fronte até as órbitas, os intervalos tão grandes como os pontos, alguns um pouco maiores, deixando uma área lisa anteocelar, a do ocelo médio deprimida; mais esparsa nas áreas paroculares deixando grande área lisa junto às suturas subantenais; esparsa no clípeo e ainda mais na supraclipeal, em ambos com micro-pontos intercalados; fina e densa no vértice; fina e esparsa nas genas, os intervalos até dois diâmetros e com micro-pontos esparsos. No mesoscuto forte porém muito esparsa (4-5 dp), ligeiramente mais densa nos cantos anteriores; no escutelo os intervalos de $2 \mathrm{dp}$, deixando área lisa triangular do disco para a base; no metanoto quase como no escutelo sem a área lisa triangular; nos mesepisternos densa em cima, mais esparsa para trás e para baixo. Nula na área basal do propódeo (um ou dois pontos perdidos na área) com toda a superfície micro-reticulada e os pontos mais densos para baixo e para os lados, muito densa abaixo do espiráculo. Muito esparsa (5-8 dp) nos três primeiros tergos com alguns micro-pontos, do quarto em diante um pouco mais densa; com micro-rúgulas nas depressões marginais; nos esternos mais densa antes das depressōes marginais e quase nula para a base.

Olhos mais longos que duas vezes sua largura; genas de perfil, apenas a metade da largura dos olhos (270: 110: 55); face pouco alargada no meio (a interorbital máxima menor que o comprimento do olho) um pouco estreitada para baixo (188: 200: 160); clípeo 1,7 vezes mais largo que longo, o comprimento cerca de cinco oitavos da distância ao ocelo (90: 145: 140), com estreita depressão marginal; malar linear (3); subantenal quese dois diâmetros de álveolo; supraclipeal no plano da face, igualmente as paroculares; distância interalveolar 2,4 vezes o diâmetro do alvéolo, a alveolocelar 1,6 (65:44:d 27); o sulco frontal fino, visível apenas na depressão anteocelar; distância interocelar igual à ocelorbital, pouco menos de dois diâmetros de ocelo(46: 45: d 25). Labro sub-trapezoidal com os cantos arredondados, um pouco mais curto que largo, o bordo anterior emarginado no meio e denticulado aos lados. Escapo subcilíndrico, quase quatro vezes seu diâmetro, mais curto que a distância alveolocelar (70/20: 90) e que os três primeiros flaglômeros juntos, cerca de $2 / 9$ do comprimento do pedicelo e flagelo juntos (310); o pedicelo bastante mais longo que seu diâmetro, o flagelômero basal longo-obcônico, duas vezes o comprimento do segundo, o terceiro tão longo como o próprio diâmetro (44: 22: 24: d 25). As margens apicais dos tergos segundo ao quarto claramente sinuadas e as depressões marginais muito estreitadas para os lados.

Macho relativamente grande. Comprimento total aproximado $9,6 \mathrm{~mm}$, da asa anterior $9,6 \mathrm{~mm}$; largura da cabeça $3,4 \mathrm{~mm}$ e do segundo tergo $3,20 \mathrm{~mm}$.

Preto, com as pernas castanhas, tarsos médios passando a ferrugineo-claros, os dois quintos distais das tíbias posteriores mais amarelados; basitarso desse par cor de cêra esbranquiçada, as unhas com as pontas pretas, os esporões pardoocráceo-claros. Tégulas pardo-escuras; asas um pouco escurecidas; estigma pardoocráceo, venação quase preta.

Pilosidade na face intensamente branca, mais densa nas paro-culares inferiores e com algumas cerdas pretas nos dois terços superiores do clípeo, na supraclipeal, paroculares superiores e vértice; palido-esbranquiçada no labro e 
genas, lateral e ventralmente no tórax, no lado póstero-externo dos fêmures anteriores e na maior parte das tíbias e tarsos de todos os pares, no lado ventral do abdômen. Pêlos plumosos brancos na parte média apical do segundo e principalmente do terceiro e quarto esternos; nestes dois últimos com cerdas longas um pouco amareladas em série marginal a cada lado e voltadas para o meio; quinto esterno quase inteiramente glabro; sexto a cada lado da porção apical com uma série de cerdas duras implantadas em saliência procurva e voltadas para dentro; nos tergos quinto e sexto com franja plumosa precedida de longas cerdas, no sétimo com longas cerdas curvadas para o disco.

Olhos duas vezes mais longos que largos; genas estreitas, menos da metade do olho de perfil (230: 110: 55); malar linear (3); órbitas internas pouco sinuadas, convergentes para baixo, distância interorbital máxima bem mais curta que o olho (180: 185: 145); clípeo levemente abaulado, pouco mais longo que metade da sua largura, distância ao ocelo médio menor que sua largura (80: 140: 135); distância interalveolar dois diâmetros e meio de alvéolo, alveolorbital cerca de um diâmetro (60: 38: d 24); supraclipeal levemente saliente; sulco frontal obsoleto, mais visivel na porção lisa anteocelar; paroculares planas; vértice atrás dos ocelos e órbital cerca de um diâmetro de ocelo, interocelar igual à ocelorbital, pouco menos de dois diâmetros de ocelo (48: 48: d 26). Labro quase tão largo como duas vezes seu comprimento, coberto com longa pilosidade plumosa branca. Escapo subcilíndrico, fracamente claviforme e um pouco arqueado, mais longo que três diâmetros, claramente mais curto que a distância alveolocelar (70/22:84), mais curto que os três primeiros flagelômeros e cerca de $1 / 5$ do comprimento do pedicelo e flagelo juntos (348); flagelômero basal obcônico, duas vezes seu diâmetro, o segundo ligeiramente mais longo que seu diâmetro, porém mais curto que o terceiro; este mais longo que seu diâmetro, dois terços do primeiro (42: 25: $28:$ d 21). As coxas posteriores com um forte espinho adunco voltado para trás: fêmures e tíbias muito robustos, engrossados; basitarsos extremamente modificados, grosso-foliformes, de contorno subtriangular, entre as articulações mais longos que sua largura apical (200:160), com a porção anterior levemente procurva e os bordos posterior e distal fracamente sinuados, o posterior mais fortemente no terço basal, o canto póstero-distal largamente arredondado, sem chegar a formar uma sola delimitada. Do segundo ao quarto tergos com o bordo marginal translúcido e um pouco sinuado; o último fracamente bilobado.

Designo o macho da série típica como Lectótipo, caindo-lhe muito bem o nome específico. O basitarso posterior é realmente notável pela sua largura e formato de folha.

Somente tenho visto exemplares do Estado de São Paulo e a espécie foi obtida de ninhos artificiais pelo grupo do Prof. C.A. Garófalo, Universidade de São Paulo - Ribeirão Preto, na Fazenda Santa Carlota, Cajuru (São Paulo, Brasil). 


\section{Tetrapedia pyramidalis Friese, 1899}

Tetrapedia pyramidalis Friese. 1899. Ann. k.k. Naturhist. Hofmus. 14 (3): 285.

Tetrapedia xanthostigma Schrottky, 1913. Deutsch. ent. Zeit- schrift.: p.706. Syn. Nov.

Brasil, Santa Catarina: Blumenau, exemplar macho, selecionado aqui como Lectótipo. Com as seguintes etiquetas originais:/Brasil Blumenau 1897/ Tetrapedia ơ pyramidalis det. Friese 1898 n. sp./, etiqueta vermelha: /Type/ e duas etiquetas em amarelo claro:/Zool. Mus. Berlin/.

Completo, em perfeito estado de conservação. Já em 1958 esta espécie havia sido reconhecida por mim como pertencente a este gênero, tendo visto um exemplar determinado por Friese no Museu Nacional de História Natural de Paris.

Diagnóstico. " $\sigma$ ". Nigra, nigro-hirta, clypei margine flavo- striato, antennis fuscis, pedibus nigris fusco-hirtis, tibiis posticis apice extus albido-fasciculatis. Tetrapedia pyramidalis steht der clypeata am nächsten, ist aber viel kleiner, hat schwarze Beine, mit fast überall schwarzer Behaarung und andere gebildetem Metatarsus". E mais adiante: "Metatarsus schwach gebogen, besonders aussen sehr lang bebüschelt, innen kahl, mit gerandeter brauner und glatter Fläche, innere Sporen hellbraun".

Macho de porte médio. Comprimento total aproximado $9,58 \mathrm{~mm}$, da asa anterior $6,5 \mathrm{~mm}$; largura da cabeça $2,25 \mathrm{~mm}$ e do segundo tergo $2,00 \mathrm{~mm}$.

Inteiramente preto; com uma faixa amarela ligeiramente arqueada no bordo anterior do clípeo, a margem superior sinuada no meio; flagelo levemente acastanhado; tíbias e tarsos posteriores castanho-avermelhados; extremidade marginal dos tergos primeiro, segundo e quarto translúcida, do terceiro mais largamente pálido-ocrácea. Tégulas pardo-escuras, lateralmente translúcidas; asas levemente escurecidas, com o estigma e R1 amarelos; venação pardo-escura, com uma linha esbranquiçada originada na base do estigma, rapidamente curvada para Rs passando pela segunda célula submarginal e terminando no terço inferior do segundo $\mathrm{r}-\mathrm{m}$.

Pilosidade predominante preta, relativamente longa e plumosa na cabeça (algumas cerdas no vértice até 400 micra), no tórax principalmente aos lados e nos flancos do propódeo; formando dois tufos no escutelo (cerdas até 1000 micra). Alguns pêlos plumosos brancos nas paroculares inferiores à altura dos alvéolos, aos lados do clípeo, nas genas junto às órbitas e no escapo; bastante desenvolvida no terço distal das tíbias médias e no sexto distal das posteriores em tufo denso-piloso-plumoso; nos basitarsos médios mais desenvolvida e mais plumosa, nos posteriores ainda mais longa e mais denso-plumosa com algumas cerdas longas entremeadas (até 700 micra) projetadas para trás. Bastante esparsa nos tergos em direção à base, mais evidente para a margem, formando franja premarginal estreita no quarto tergo, muito mais densa no quinto e em todo o sexto, com o ápice dos pêlos cinza-esbranquiçados nos tergos quinto e sexto, alguns pêlos pálidos castanhos ao longo do meio da densa pilosidade do sexto tergo. Os dois primeiros esternos com pilosidade rala; no terceiro e quarto denso-plumoso-esbranquiçada seguida de franja marginal estreita e aos lados com uma série de longas cerdas 
plumosas voltadas para dentro; no quinto a área apical esbranquiçado-plumosa bastante reduzida, no sexto um tufo de pêlos pretos mais curtos a cada lado da carena média, voltados para trás e para o meio.

Pontuação moderadamente grossa, bastante densa na fronte, os intervalos lisos cerca de $2 \mathrm{dp}$, nos lados acima dos alvéolos bastante densa deixando ampla área lisa pré-ocelar estendida até as paroculares superiores, para baixo acima da área supraclipeal um pouco mais fina e mais densa; no clípeo e na supraclipeal muito esparsa (mais de $3 \mathrm{dp}$ ), os pontos como que biselados, inclinados, na supraclipeal; fina e esparsa nas paroculares inferiores; no vértice e entre os ocelos bastante fina e densa, nas genas um pouco mais esparsa deixando estreita faixa lisa ao longo da órbita. No mesoscuto mais densa, os intervalos careniformes entre o sulco médio e as parápsides e mais fina no disco, mais grossa e esparsa para trás e para os lados; no escutelo mais fina e densa, ainda mais no metanoto; nos lados dos mesepisternos forte e densa. No propódeo a área basal com pontos quase como os intervalos. Os quatro primeiros tergos largamente lisos nos três quartos basais com poquíssimos pontos, mais numerosos no quarto distal; no quinto tergo o terço basal liso e brilhante os dois distais cobertos por densa pilosidade plumosa, o sexto todo coberto pelo mesmo tipo de pilosidade; o sétimo largamente liso, com poucos pontos pilígeros posteriormente. Esternos largamente lisos na base, com pontos pilígeros na porção posterior, poucos no primeiro e segundo, numerosos nos seguintes e entrando mais para a base, no quinto fina e mais uniforme; no sexto em tufos nos lados e, uma carena lisa no meio.

Olhos pouco mais longos que duas vezes sua largura; genas, de perfil, mais estreitas que os olhos (155: 70: 40); malar linear (2); face moderadamente estreitada para baixo, a distância inter-orbital máxima claramente menor que o comprimento do olho (122: 130: 102); clípeo um pouco mais longo que a metade da sua largura e menos de dois terços da sua distância ao ocelo médio (65: 100: 95), apenas levemente abaulado com os cantos inferiores fracamente marcados e muito próximos às órbitas; as subantenais tão longas como o alvéolo; a supraclipeal pouco destacada; a distância interalveolar 1,75 vezes o diâmetro do alvéolo e a alveolorbital apenas 1,45 (35: 29: d 20); áreas paroculares planas; sulco frontal um tanto obsoleto chegando até a área lisa preocelar; distância interocelar menos de dois diâmetros de ocelo e um pouco maior que a ocelorbital (35: 30: d 23); vértice largo. Labro três quartos mais curto que largo na base, deprimido ao longo do meio, os lados convergentes para o ápice, este levemente sinuado. Escapo subcilíndrico, fracamente alargado para o ápice, três vezes seu diâmetro, um pouco mais curto que a distância alveolocelar $(50 / 17: 60)$, pouco mais de $3 / 8$ do comprimento do flagelo e pedicelo juntos (130), um pouco mais curto que os três primeiros flage-lômeros juntos; flagelômero basal obcônico quase 1,8 vezes seu diâmetro apical, o segundo o mais curto, o terceiro igual ao seu diâmetro (25: 14 : 15: d 15). No mesoscuto as parápsides mais evidentes que o sulco médio; escutelo plano; mesepisternos arredondados na passagem para a face anterior, sem formar dobra; esporão médio curto, fortemente adunco; basitarso posterior pouco modificado, mais longo que largo, fracamente dilatado para o ápice e um pouco curvo, com a sola lisa, arqueada para dentro, estreita, terminando em ponta largamente 
arredondada, lateralmente com algumas cerdas.

Friese viu numerosos exemplares do Brasil: Santa Leopoldina (Espírito Santo), Ipanema (São Paulo) e Blumenau (Santa Catarina). Até o presente não ví exemplares desta espécie em nenhuma das coleções que tenho estudado.

Friese pensava tratar-se do macho de T. rugulosa, que também não conheço in natura. Realmente a fêmea desta espécie foi descrita por Schrottky, em 1913, como Tetrapedia xanthostigma.

Estranho o nome dado à espécie, pois nada vejo de piramidal nas pernas posteriores ainda que as tíbias engrossadas para o ápice pareçam mais volumosas pela pilosidade plumosa que as reveste. Nos basitarsos posteriores a longa pilosidade escura é muito densa, pouco deixando ver do contorno posterior dos mesmos. Carácter verdeiramente notável constitui a passagem suavemente arredondada da face lateral do mesepisterno para a anterior, sem dobra em carena. $\mathrm{O}$ formato e densa pontuação do propódeo e, a densa e longa pilosidade preta dos mesepisternos são bons diagnósticos juntamente com o desenho amarelo do clípeo.

AGRADECIMENTOS. Agradeço aos Drs. Günther Peters e Franz Koch, do Museu Zoológico da Universidade Humboldt de Berlin, ao Dr. E. Diller do Zoologische Staatssammlung. Munique e ao Dr. D. Wittmann, da Universidade de Tühingen, a intermediação para ter em mãos esses exemplares. Ao Prof. C.D. Michener a possibilidade de minha primeira viagem à Europa.

\section{REFERÊNCIAS BIBLIOGRÁFICAS}

FrIESE, H. 1899. Monographie der Bienengattungen Exomalopsis, Ptilothrix, Melitoma, und Tetrapedia. Ann. k.k. Naturhist. Hofmus., Wien, 14 (3): 247-304.

Michener, C. D. \& J. S. Moure. 1957. A study of the classifiction of the more primitive non-parasitic Anthophorine bees (Hymenoptera, Apoidea). Bull. Amer. Mus. Nat. Hist. 112: 395-452.

SchrotTky, C. 1913, Neue südamericanische Hymenopteren. Deutsch ent. Zeitschrift: 706-708. 